\title{
Correction to: Medical Image Watermarking in Transform Domain
}

\author{
Harsh Vikram Singh and Ankur Rai
}

\section{Correction to:}

Chapter "Medical Image Watermarking in Transform

Domain" in: S. Tiwari et al. (eds.), Smart Innovations

in Communication and Computational Sciences, Advances

in Intelligent Systems and Computing 851, https://doi.org/10.1007/978-981-13-2414-7_45

In the original version of the book, the following belated correction has been incorporated: The affiliation of Ankur Rai has been changed from "Kamla Nehru Institute of Technology, Sultanpur 228118, India" to "Assistant Professor, Electronics and Communication Engineering, Invertis University, Bareilly 243123, Uttar Pradesh, India". The erratum chapter and the book have been updated with the change. 